\title{
PENGETAHUAN IBU RUMAH TANGGA TERHADAP GARAM BERYODIUM
}

\author{
Ida Mariana \\ Akper Kesdam 1/BB Padang Indonesia \\ e-mail: idamariana1992@gmail.com
}

\begin{abstract}
Abstrak
GAKY atau Gangguan Akibat Kekurangan Yodium adalah salah satu masalah gizi yang menjadi faktor penghambat pembangunan SDM karena hal ini dapat menyebabkan terganggunya perkembangan mental dan kecerdasan terutama pada anak-anak. GAKY diketahui mempunyai dampak negatif seperti gondok dan kretinisme dan sangat berpengaruh terhadap kualitas kehidupan manusia secara luas meliputi tumbuh kembang, termasuk perkembangan otak dan keberlangsungan kesehatan tubuh. Kekurangan yodium pada ibu hamil dapat berakibat pada keguguran, dan bayi lahir mati dan bayi lahir kretin. Tujuan penelitian ini untuk mengetahui gambaran pengetahuan ibu rumah tangga terhadap garam beryodium. Jenis penelitian ini adalah penelitian kuantitatif. Teknik pengambilan sampel dengan menggunakan simple random sampling sebanyak 88 ibu rumah tangga. Hasil penelitian menunjukkan dari 88 ibu $(61,3 \%)$ memiliki pengetahuan kurang baik, dan $(38,7 \%)$ pengetahuan baik. Hasil penelitian menunjukan bahwa pengetahuan ibu rumah tangga yang paling banyak yaitu pada pengetahuan kurang tentang GAKY .
\end{abstract}

Kata Kunci : Pengetahuan, Garam Beryodium. GAKY, Gangguan Akibat Kekurangan Yodium, gizi, kretin, SDM

\begin{abstract}
GAKY or Iodine Deficiency Disorders is one of the nutritional problems which is an inhibiting factor in the development of human resources because this can cause disruption of mental development and intelligence in children. GAKY has negative impacts such as mumps and cretinism and is closely related to the quality of human growth and development, including brain development and health continuity. Lack of iodine in pregnant women can result in miscarriage, and stillbirths and cretins. The purpose of this study was to study housewives' knowledge of iodized salt. This type of research is quantitative research. The sampling technique used was simple random sampling of 88 housewives. The results showed that of 88 mothers (61.3\%) had poor knowledge, and (38.7\%) good knowledge. The results showed that the knowledge of housewives had the most lack of knowledge about GAKY.
\end{abstract}

Keywords: Knowledge, Iodized Salt. GAKY, Disorders Due to Iodine Deficiency, nutrition, cretin, Human Resources 


\section{PENDAHULUAN}

Yodium adalah mineral yang terdapat di alam baik di tanah maupun di air yang menjadi salah satu zat gizi yang berperan pada sintesis hormon Tiroid, dan berperan penting juga pada fungsi organ tubuh, dan proses tumbuh kembang terutama pada perkembangan otak dimasa bayi. (Nurcahyani, dkk, 2010).

GAKY atau Gangguan Akibat Kekurangan Yodium merupakan kumpulan gejala yang timbul akibat tubuh kekurangan yodium terus menerus dalam jangka waktu cukup lama. Gejala ini dapat menyerang siapa saja baik Perempuan, Pria, Lansia, maupun pada anakanak.(Ridho Pratama, 2015).

Menurut Survey Nasional Pemetaan GAKY di seluruh Indonesia pada tahun 2003 (kecuali di Nanggroe Aceh Darussalam dan Papua), didapatkan $8,8 \%$ kabupaten/kota endemik berat, 12,2\% kabupaten/kota endemik sedang, $35,7 \%$ endemik ringan, dan $43,3 \%$ termasuk non endemik. Dan beberapa survey juga menunjuan dari hasil survey tersebut banyak masyarakat yang mengalami penyakit pembesaran kelenjar thyroid atau menderita penyakit gondok. Selain berupa pembesaran kelenjar gondok dan hipotiroid, kekurangan unsur yodium dalam tubuh dapat menyebabkan gangguan mental, gangguan pendengaran, gangguan perkembangan pada anak dan dewasa, untuk wanita hamilpun hal ini akan memberikan dampak serius seiring dengan kadar hormon rendah sehingga hal ini dapat menjadikan angka lahir dan angka kematian janin meningkat Ahdani Subhan (2015).
Hal ini di dukung oleh penelitian penelitian Cahyana K.Widada (2014) yaitu terdapat perbedaan antara aktifitas fisik dan prestasi belajar anak penderita GAKY dan non GAKY dengan ditunjukan hasil nilai $\mathrm{p}$ berturut turut yaitu $\mathrm{p}=0,000$ dan $\mathrm{p}=0,004$.

Penggunaan garam beryodium pada masyarakat tidaklah sulit karena bisa digunakan secara praktis pada setiap makanan, dengan cara menambahkan garam beryodium. Selain itu, kebutuhan yodium bisa didapat dari berbagai sumber makanan laut seperti ikan, kerang, rumput laut, serta makanan produk pertanian pada wilayah pegunungan dimana makanan tersebut dihasilkan.

Sijunjung merupakan suatu daerah yag terdapat di wilayah Provinsi Sumatera Barat, dengan jumlah 61 desa dengan jumlah penduduk 46.580 Jiwa. Jorong Tapian Anto merupakan Jorong yang terdapat di Wilayah kabupaten Sijunjung. Pada tanggal 13 bulan Januari 2020 telah di lakukan survey awal Dari 30 Ibu rumah tangga yang di wawancarai 28 diantaranya tidak mengerti tentang GAKY dan tidak mengerti manfaat dari garam yodium. Dari data tersebut peneliti tertarik untuk meneliti tentang gambaran Pengetahuan Ibu Rumah Tangga Terhadap Garam Beryodium Di Jorong Tapian Anto Kecamatan Sijunjung.

\section{METODE}

Penelitian ini adalah penelitian kuantitatif, sampel diambil secara Total sampling yaitu seluruh populasi dijadikan sampel sebanyak 88 Orang ibu rumah tangga. Data didapatkan dengan cara pengisian kuesioner yang telah disiapkan tekait Pengetahuan ibu 
HASIL

\section{Analisis Univariat}

Hasil penelitian menunjukan karakteristik ibu rumah tangga yang meliputi Pengetahuan ibu hamil yang dapat dilihat pada tabel 1 .

Tabel 1. Distribusi Frekuensi Pengetahuan ibu terhadap garam beryodium

\begin{tabular}{|l|c|c|}
\hline Pengetahuan & Frekuensi & \% \\
\cline { 1 - 2 } Baik & 34 & 38,7 \\
\cline { 1 - 2 } Kurang Baik & 54 & 61,3 \\
\cline { 1 - 2 } Jumlah & $\underline{\mathbf{8 8}}$ & $\mathbf{1 0 0}$ \\
\cline { 1 - 2 } & &
\end{tabular}

Berdasarkan tabel 1 terlihat bahwa sebanyak $61,3 \%$ responden memiliki pengetahuan kurang baik.

\section{PEMBAHASAN}

Berdasarkan hasil pengisian kuesioner oleh 88 ibu rumah tangga di Jorong Tapian Anto di dapatkan gambaran pengetahuan ibu rumah tangga tentang garam beryodium dari 88 orang ibu rumah tangga 54 (61,3\%) ibu rumah tangga memiliki pengetahuan kurang baik dan 34 $(38,7 \%)$ ibu rumah tangga memiliki pengetahuan baik. Dapat diartikan bahwa di Jorong Tapian Anto ibu rumah tangga memiliki pengetahuan yang rendah terhadap manfaat garam beryodium, dan masih kurang dalam mengetahui sumber yodium. Hal ini dilihat dari ibu rumah tangga yang kurang mampu memaparkan manfaat garam beryodium dan tidak mampu memaparkan akibat kekurangan garam beryodium selain gondok. Seperti halnya dalam penelitian (Hartati, 2013) yang menyatakan ada hubungan antara pengetahuan ibu rumah tangga tentang akibat kerurangan garam beryodium dengan perilaku ibu rumah tangga terhadap penggunaan garam beryodium.

Jadi dapat disimpulkan secara keseluruhan bahwa ibu rumah tangga di Jorong Tapian Anto belum memahami tentang pentingnya mengkonsumsi garam beryodium dan cara penggunaan garam beryodium yang benar dan minimnya pengetahuan ibu rumah tangga di Jorong Tapian Anto mengenai sumber yodium lainnya, pengertian garam beryodium, akibat kekurangan garam beryodium dan cara menggunakan garam beryodium yang benar.

\section{KESIMPULAN}

Dalam penelitian ini dapat disimpulkan bahwa dari 88 ibu rumah tangga yang menjadi responden 54 (61,3\%) diantaranya memiliki pengatuan yang kurang terhadap GAKY. Hal ini terlihat dari Minimnya pengetahuan ibu rumah tangga di Jorong Tapian Anto memahami mengenai sumber yodium lainnya, pengertian garam beryodium, akibat kekurangan garam beryodium dan cara menggunakan garam beryodium yang benar.

\section{SARAN}

Penelitian ini hanya meneliti satu variabel saja dan dengan responden yang relatif sedikit, sehingga hanya menggambarkan hasil penelitian yang sederhana, untuk itu, agar penelitian lanjutan menggunakan jumlah responden yang lebih besar dan dengan cakupan wilayah kerja yang lebih luas, serta dapat menambah variabel penelitian dengan menghubungkan pengetahuan dan sikap, perilaku responden.

\section{DAFTAR PUSTAKA}

Agrivin, (2016). Hubungan Antara Pengetahuan Ibu Tentang Garam Beryodium Dan Pola Konsumsi 
Zat Goitrogenik Terhadap Kadar Ekskresi Yodium Urin Siswa Sdn 4 Krebet Kecamatan Jambon Kabupaten Ponorogo

Depkes, RI. (2009). Garam Beryodium Jakarta: Departemen Kesehatan RI

Hariyanti, W. d. (2010). Hubungan Antara Sikap Terhadap Penggunaan Garam Beryodium Dengan Kejadian Gondok Pada Wanita Usia Subur Jurnal

Hartati. (2013). Hubungan Pengetahuan Terhadap Perilaku Ibu Rumah Tangga Dalam Penggunaan Garam Beryodium Di Desa Sengo Selatan Kecamatan Belova Di Kabupaten Luwu.

Wariyanto. (2013). Akselerasi Adopsi Inovasi Penggunaan Garam Beryodium : Model Penanganan Berbasis Masyarakat Menuju Bebas GAKY. 
